\title{
Structural and Phase Transformations in Water-Vapour-Plasma-Treated Hydrophilic $\mathrm{TiO}_{2}$ Films
}

\author{
L. Pranevicius, M. Urbonavicius, S. Tuckute, K. Gedvilas, T. Rajackas, \\ L. L. Pranevicius, and D. Milcius
}

Physics Department, Vytautas Magnus University, Vileikos Street 8, 44404, Kaunas, Lithuania

Correspondence should be addressed to L. Pranevicius, l.pranevicius@gmf.vdu.lt

Received 23 March 2012; Revised 2 July 2012; Accepted 7 July 2012

Academic Editor: Markku Leskela

Copyright (C) 2012 L. Pranevicius et al. This is an open access article distributed under the Creative Commons Attribution License, which permits unrestricted use, distribution, and reproduction in any medium, provided the original work is properly cited.

\begin{abstract}
We have investigated structural and phase transformations in water-vapor-plasma-treated 200-300 nm thick Ti films, maintained at room temperature, by injecting water vapor into radio frequency $(\mathrm{RF})$ plasma at different processing powers. Scanning electron microscopy (SEM) combined with optical microscopy and surface nanotopography analysis were used to view tracks of adsorbed water layers and to detect bulges or blisters appeared on the surface of treated samples. Rough surfaces with different size of holes $(5-20 \mu \mathrm{m})$ through the entire film thickness have been observed. X-ray diffraction results show that the oxidation rate of Ti film drastically increases in the presence of an adsorbed water on the hydrophilic layer. It is assumed that the defining factor which controls oxidation kinetics is the hydroxyl radicals formation.
\end{abstract}

\section{Introduction}

Exposition of $\mathrm{Ti}$ surfaces in water vapor results in the formation of an adsorbed layer on the surface. Rapid diffusion on the surface maintains quasiequilibrium between the molecules bound to islands and isolated adsorbed water molecules. Water molecules oxidize Ti atoms $\left(\mathrm{Ti}_{x} \mathrm{O}_{y}+(2 x-\right.$ y) $\left.\mathrm{H}_{2} \mathrm{O}=x \mathrm{TiO}_{2}+(2 x-y) \mathrm{H}_{2}\right)$. These possible oxidation reactions are highly thermodynamically favorable and form nanostructured hydrated titanium oxide layer [1]. It is known that the thermal oxidation of titanium by water vapor proceeds according to a linear-parabolic rate law resulting from a reaction-diffusion-mixed regime. The growth of $\mathrm{TiO}_{2}$ takes place by rapid diffusion of substitutional hydroxide ions generated at the gas-scale interface [2].

It is established [3] that the titanium coating exposed to ultraviolet light has the extraordinary property of complete wettability for water. The ultraviolet light removes some of the oxygen atoms from the surface of the titania, resulting in a patchwork of nanoscale domains where hydroxyl groups became adsorbed, which produces the superhydrophilicity. It is proved that the $\mathrm{Ti}^{3+}$ ions are closely associated with the hydrophilicity of $\mathrm{TiO}_{2}[4,5]$.

Titanium coatings immersed in plasma are exposed to ultraviolet radiation and ion bombardment $[6,7]$. Due to radiation coming from the plasma, oxygen atoms are preferentially removed from the surface of titania and the formation of suboxides as well as an oxygen deficient surface in the steady state is registered [8]. The water molecules arriving at the plasma activated surface due to hydrophilicity tend to spread out over the entire surface, as schematically shown in Figure 1.

Under plasma radiation the split of hydroxyl radicals, resulting from dissociation of water molecules and oxidation of $\mathrm{Ti}$, into their atomic components: hydrogen and oxygen occurs [4]. The hydrogenation of growing titanium oxide $\mathrm{TiO}_{2}$ takes place [9].

The present paper reports the study of the structural and phase transformations in thin Ti films treated by water vapor plasma in dependence to the surface coverage by hydrophilic layer at different levels of processing power.

\section{Experimental Technique}

The vacuum $80 \mathrm{~L}$ volume stainless steel chamber is equipped with a water inlet valve, which permits the introduction of water vapor from outside the chamber. The Ti samples to be treated are placed onto the water-cooled substrate holder. The reaction chamber is evacuated using a turbomolecular 

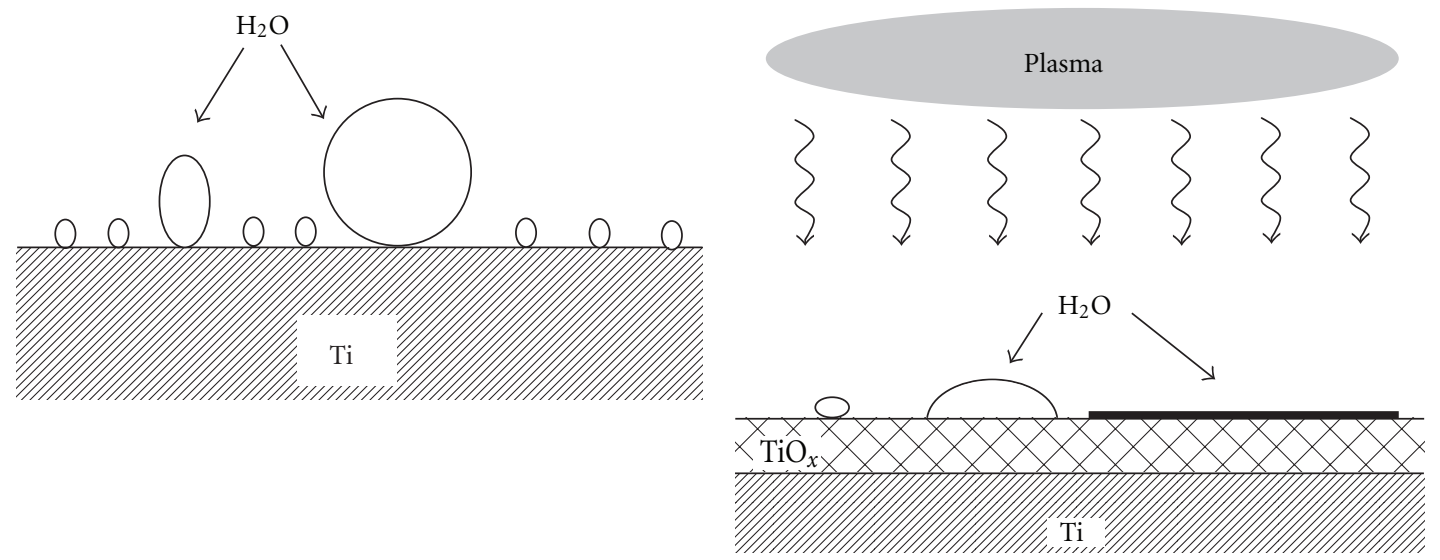

(a)

(b)

FIGURE 1: Formation of water layer on the hydrophilic surface: (a) adsorbed water on a plasma nonactivated surface and (b) water layer on a plasma-activated surface.

vacuum pump down to a pressure of about $10^{-3} \mathrm{~Pa}$ and then connected to the source of water vapor. Once the steady state of water vapor pressure of about 5 to $10 \mathrm{~Pa}$ in the chamber at ambient temperature is reached, the $\mathrm{Ti}$ sample is exposed to low-pressure RF plasma. The discharge characteristics have been controlled using a variable RF power supply by changing input power levels from 50 to $300 \mathrm{~W}$. Without an applied axial magnetic field, plasma ionization degree increases linearly with plasma dissipated power. With an axial magnetic field, ionization degree jumps to a maximum value at about $300 \mathrm{~W}$ and then saturates. The positive ion density and electron density of the vapor plasma of around $5 \cdot 10^{10} \mathrm{~cm}^{-3}$ and the electron temperature between 1.2 and $1.6 \mathrm{eV}$ were measured by a Langmuir probe at processing power of $300 \mathrm{~W}$. It is in close agreement with the experimental results presented in [6].

The microstructure of the samples was characterized by X-ray diffraction (XRD) method using Bruker diffractometer (Bruker D8). The measurements were performed with $2 \theta$ angle in the range $20^{\circ}-70^{\circ}$ using $\mathrm{Cu}$ cathode $\mathrm{K} \alpha$ radiation in steps of $0.01^{\circ}$. All X-ray diffraction peaks were indexed using software together with Search-Match function and PDF-2 database from International Centre for Diffraction Data (ICDD). The thickness and surface topography of $\mathrm{Ti}$ films were measured using the nanoprofilometer (AMBIOS XP 200). The spatial resolution was several nanometers. The surface views were investigated before and after plasma treatment by the scanning electron (SEM, JEOL JSM-5600) and optical (Nikon Eclipse Lv150) microscopes. The distribution profiles of oxygen in Ti films were measured by Auger Electron Spectroscopy (AES, PHI 700XI). The distribution profiles of hydrogen in Ti films after hydrogenation were measured by Glow Discharge Optical Emission Spectroscopy (GDOES, Spectruma Analytic GMBH).

\section{Experimental Results}

Water vapor condenses on the hydrophilic Ti surface in plasma surrounding to produce adsorbed water layer. The distribution and size of water island layers on the surface of thin hydrophilic Ti film surface were investigated by trace analysis of islands on the surface of plasma-treated samples using optical and scanning electron microscopes. It was found that water island layers were randomly distributed on the surface with an average size of about $8 \mu \mathrm{m}$.

Figure 2 includes SEM surface views of plasma-treated Ti films: (a) at $50 \mathrm{~W}$ for $60 \mathrm{~min}$ and (b) at $300 \mathrm{~W}$ for $5 \mathrm{~min}$. We observed that Ti films treated upon lightly ionized water vapor plasma (at RF power equal to $50 \mathrm{~W}$ ) are homogeneous and smooth (Figure 2(a)). After treatment by highly ionized water vapor plasma (at RF power equal to $300 \mathrm{~W}$ ), holes throughout the entire film thickness were observed (Figure $2(\mathrm{~b}))$. With an increase in the power dissipation in plasma, the density of holes increased while the mean size remained about the same. The SEM surface view also reveals the circular bumps distributed between the holes (Figure 2(b)).

Figure 3 includes surface height profiles of untreated Ti film (Figure 3(a), curve 1) and plasma treated at $50 \mathrm{~W}$ for $60 \mathrm{~min}$ (Figure 3(a), curve 2). It was registered that the surface topography, initially flat with a mean roughness of about $2 \mathrm{~nm}$, becomes periodically bumpy with a height amplitude equal to $8 \mathrm{~nm}$ and a period equal to $15-18 \mu \mathrm{m}$ after treatment at $50 \mathrm{~W}$ for $60 \mathrm{~min}$. As the output power of the RF power amplifier increased, the surface was subjected to the development of various bumps and blisters. After exposition to the water vapor plasma at $300 \mathrm{~W}$ for $5 \mathrm{~min}$, thin film that covered blisters was lifted and film contained randomly distributed small holes throughout the entire film thickness (Figure 3(b)), a process known as "plasma-cut". The location of the cuts correlates well with the wetted areas on the surface and can be explained by damageinduced in-plane stress and the corresponding elastic out-ofplane strain. We suppose that a rapid uptake of oxygen and hydrogen through the surface areas covered by island layers of adsorbed water occurs and deduces that fast $\mathrm{H}$ transients because of their high mobility may be responsible for the high compressive stresses which lead to film surface plastic deformation (50 W, Figure 3(a), curve 2) and detachment in 


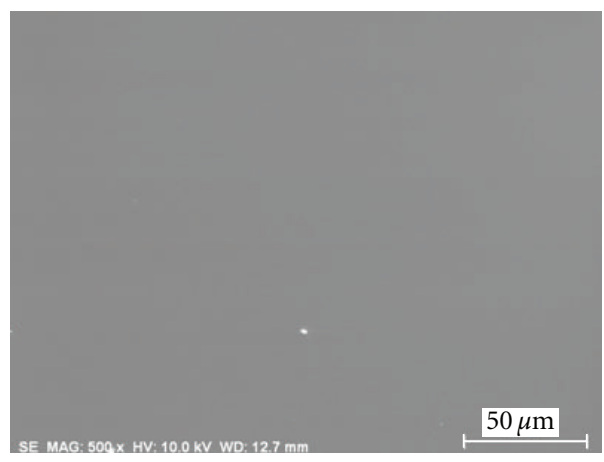

(a)

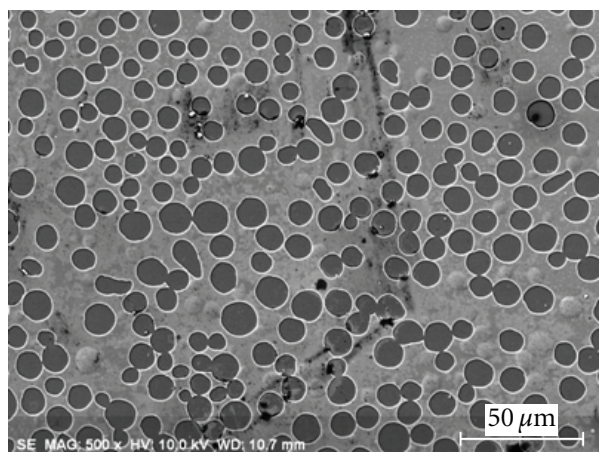

(b)

Figure 2: SEM surface views of plasma-treated Ti films: (a) $50 \mathrm{~W}$ for $60 \mathrm{~min}$ and (b) $300 \mathrm{~W}$ for 5 min.

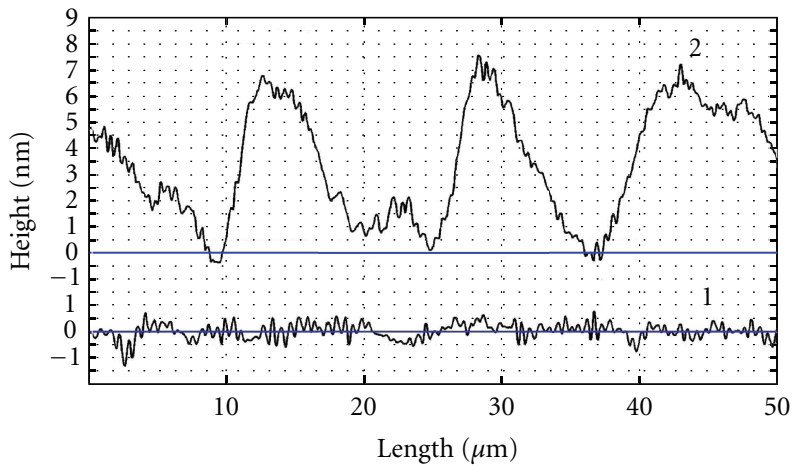

(a)

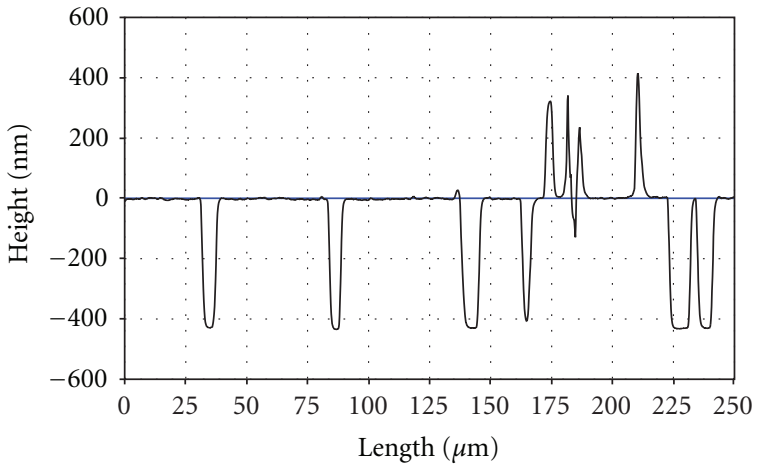

(b)

Figure 3: Surface height profile of Ti film: (a) untreated (Figure 3(a), curve 1) and plasma treated at $50 \mathrm{~W}$ for 60 min (Figure 3(a), curve 2), (b) plasma treated at $300 \mathrm{~W}$ for $5 \mathrm{~min}$ (Figure $3(\mathrm{~b})$ ).

a form of buckling or debonding from the surface of the substrate $(300 \mathrm{~W}$, Figures $2(\mathrm{~b})$ and $3(\mathrm{~b}))$.

In all cases, the mean surface roughness increases after plasma treatment. It is in agreement with other observations [10]. In the presented work, it was registered that the mean surface roughness of untreated samples is equal to 2-4 nm. It increases from $24 \mathrm{~nm}$ for samples treated at $200 \mathrm{~W}$ during $5 \mathrm{~min}$ and up to $180 \mathrm{~nm}$ for samples treated at $300 \mathrm{~W}$ during $5 \mathrm{~min}$. It is established that the dominant technological parameter to the surface roughness is the RF power, while the plasma treatment time has significantly less effect.

Water-plasma-treated hydrophilic Ti films, which had been completely covered by water layer, were subsequently analyzed by XRD technique. Figure 4 includes XRD patterns of untreated (curve 1) and plasma-treated Ti films: curve 2 for $5 \mathrm{~min}$ at $200 \mathrm{~W}$, curve 3 for $20 \mathrm{~min}$ at $200 \mathrm{~W}$, and curve 4 for $5 \mathrm{~min}$ at $300 \mathrm{~W}$. It is seen that phase and structural transformations in metallic $\mathrm{Ti}$ depend on the $\mathrm{RF}$ power dissipated in the plasma. SEM analysis showed that the Ti films entirely covered by hydrophobic layer were broken and lifted from the substrate after treatment at $300 \mathrm{~W}$ for $5 \mathrm{~min}$. It is in agreement with observation of lifting, rupture, and formation of holes for a film covered by water island layers registered by SEM (Figures 2(b) and 3(b)).
Figure 5 includes the distribution profiles of $\mathrm{O}$ and $\mathrm{H}$ atoms (curves 1 and 2, resp.) in Ti film treated at $200 \mathrm{~W}$ for $5 \mathrm{~min}$. The Auger oxygen depth profile (Figure 5, curve 1) shows a sharp decrease of oxygen concentration from 75 at. $\%$ at the surface followed by a gradual decrease through the entire film thickness in the bulk to the values around the maximum solubility of oxygen in titanium (34 at. \%), while $\mathrm{H}$ atoms are homogeneously distributed over the estimated film thickness of about $500 \mathrm{~nm}$ (Figure 5, curve 2) except the sharp increase near the surface where the mobile $\mathrm{H}$ atoms are trapped at radiation defects in $\mathrm{TiO}_{2}$. Titanium film treated at $300 \mathrm{~W}$ for $5 \mathrm{~min}$ becomes completely oxidized, while the distribution profile of $\mathrm{H}$ atoms does not change significantly in the bulk, and $\mathrm{H}$ maximum appears at the film-substrate interface. As a result of $\mathrm{H}$ accommodation at the interface, the surface is subject to the development of various bumps and blisters.

\section{Discussions}

Water molecules present in plasma are excited, ionized, and disassociated in dependence on the plasma processing power. In this surrounding, the oxygen atoms are preferentially removed from the oxidized titanium surface 


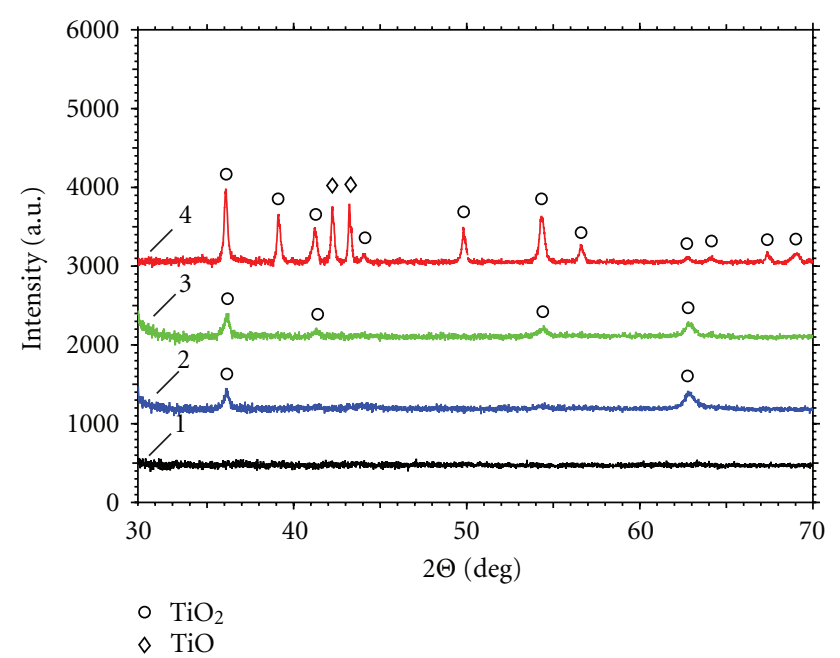

FIGURE 4: XRD patterns of Ti film after plasma treatment: 1 as deposited, 2 for $5 \mathrm{~min}$ at $200 \mathrm{~W}, 3$ for $20 \mathrm{~min}$ at $200 \mathrm{~W}$, and 4 for $5 \mathrm{~min}$ at $300 \mathrm{~W}$.

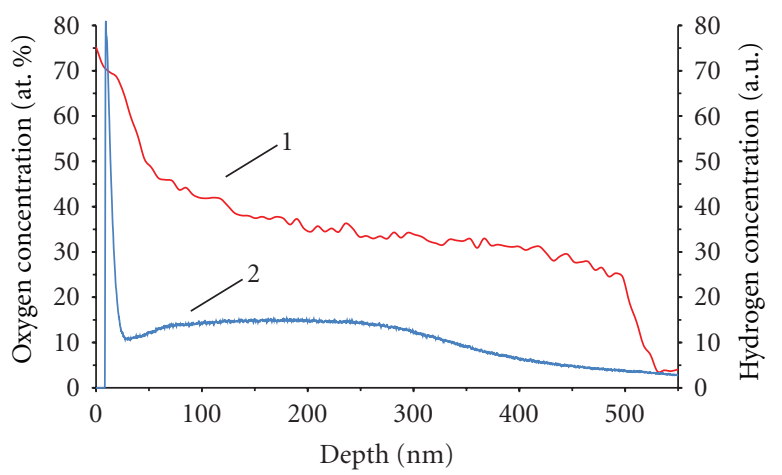

Figure 5: Distribution profiles of $\mathrm{O}$ and $\mathrm{H}$ atoms (curves 1 and 2, resp.) in Ti film treated at $300 \mathrm{~W}$ for $5 \mathrm{~min}$.

due to radiation coming from plasma. An oxygen-deficient surface with suboxides becomes highly reactive. Taking into account supperhydrophilic properties of titania, adsorbed water molecules and water drops converge to island layers rapidly. The adsorbed water molecules quickly hydrate the surface leading to increased hydroxyl group density on the surface and transformation of reduced oxides into $\mathrm{TiO}_{2}$. The concentration of hydroxyl groups on the surface depends on the oxidation state of titanium oxide. Irradiation of surface area covered by adsorbed water layer leads to the split of hydroxyl radicals into their atomic components hydrogen and oxygen $[7,10]$. These factors contribute to the increase of oxidation rate of surfaces covered by water layers. This increase is predominantly determined by the plasma radiation intensity. Additionally, the outermost layer becomes highly defected and new pathways for the transport of water molecules and atoms become possible.

The splitted $\mathrm{H}$ atoms in the near-surface region of $\mathrm{TiO}_{2}$ are trapped at radiation defects while the mobile $\mathrm{H}$ atoms detrapped from trapping centers diffuse through the oxide layer into the bulk and, taking into account titanium's high affinity for hydrogen, are absorbed by the titanium and consequently are stored in the bulk. Substantial excess of atomic hydrogen present may be accommodated in the crystal lattice, resulting in gas bubbles. Lifting in the form of "popping off" discrete blisters was observed. The size distribution of the holes correlates well with the topology of island water layers observed by SEM. One of the main issues concerning their mechanical performance is the type and magnitude of residual stresses around the crystalline $\mathrm{TiO}_{2}$ phase in the matrix of Ti. Residual stresses may or may not generate microcracks around the precipitates depending on their magnitude, crystal size, and film thickness.

\section{Conclusions}

In summary, it emerges from our results that the study of structural and phase transformations in water-vaporplasma-treated $\mathrm{Ti}$ films in dependence on the processing parameters provides an information for an advancing knowledge of the behavior of adsorbed water molecules on the surface of titanium oxide under plasma radiation. Adsorbed water molecules on the hydrophilic surface converge to water island layers leading to increased hydroxyl group density on the oxidized Ti surface and its transformation into $\mathrm{TiO}_{2}$. The $\mathrm{H}$ atoms are trapped at radiation defects in the near-surface region of $\mathrm{TiO}_{2}$, while the mobile $\mathrm{H}$ atoms diffuse through the oxide layer and tend to form gas bubbles in the bulk and at the film-substrate interface.

\section{Acknowledgments}

This research was funded by a Grant (ATE-2011/2012) from the Research Council of Lithuania. The authors are grateful to the Science Council of The Lithuanian Energy Institute and Vytautas Magnus University for the support of this research.

\section{References}

[1] P. Pérez, "On the influence of water vapour on the oxidation behaviour of pure Ti," Corrosion Science, vol. 49, no. 3, pp. 1172-1185, 2007.

[2] F. Hua, K. Mon, P. Pasupathi, G. Gordon, and D. Shoesmith, "A review of corrosion of titanium grade 7 and other titanium alloys in nuclear waste repository environments," Corrosion, vol. 61, no. 10, pp. 987-1003, 2005.

[3] A. Fujishima, T. N. Rao, and D. A. Tryk, "Titanium dioxide photocatalysis," Journal of Photochemistry and Photobiology C, vol. 1, no. 1, pp. 1-21, 2000.

[4] R. Abe, "Recent progress on photocatalytic and photoelectrochemical water splitting under visible light irradiation," Journal of Photochemistry and Photobiology C, vol. 11, no. 4, pp. 179-209, 2010.

[5] T. Ihara, M. Miyoshi, M. Ando, S. Sugihara, and Y. Iriyama, "Preparation of a visible-light-active $\mathrm{TiO}_{2}$ photocatalyst by RF plasma treatment," Journal of Materials Science, vol. 36, no. 17, pp. 4201-4207, 2001.

[6] S. V. T. Nguyen, J. E. Foster, and A. D. Gallimore, "Operating a radio-frequency plasma source on water vapor," Review of Scientific Instruments, vol. 80, no. 8, Article ID 083503, 8 pages, 2009. 
[7] J. S. Oh, K. Kawamura, B. K. Pramanik, and A. Hatta, "Investigation of water-vapor plasma excited by microwaves as ultraviolet light source," IEEE Transactions on Plasma Science, vol. 37, no. 1, pp. 107-112, 2009.

[8] T. Kubart, T. Nyberg, and S. Berg, "Modelling of low energy ion sputtering from oxide surfaces," Journal of Physics D, vol. 43, no. 20, Article ID 205204, pp. 1-18, 2010.

[9] S. Tuckute, L. L. Pranevicius, L. Pranevicius, and M. Urbonavičius, "Oxygen implantation and behaviour into Ti thin films from water vapour plasma," in Proceedings of the 1st International Conference Nanomaterials: Application \& Properties, vol. 1, pp. 390-396, Alushta, Crimea, Semptember 2011.

[10] O. Zywitzki, T. Modes, P. Frach, and D. Glöss, "Effect of structure and morphology on photocatalytic properties of $\mathrm{TiO}_{2}$ layers," Surface and Coatings Technology, vol. 202, no. 11, pp. 2488-2493, 2008. 

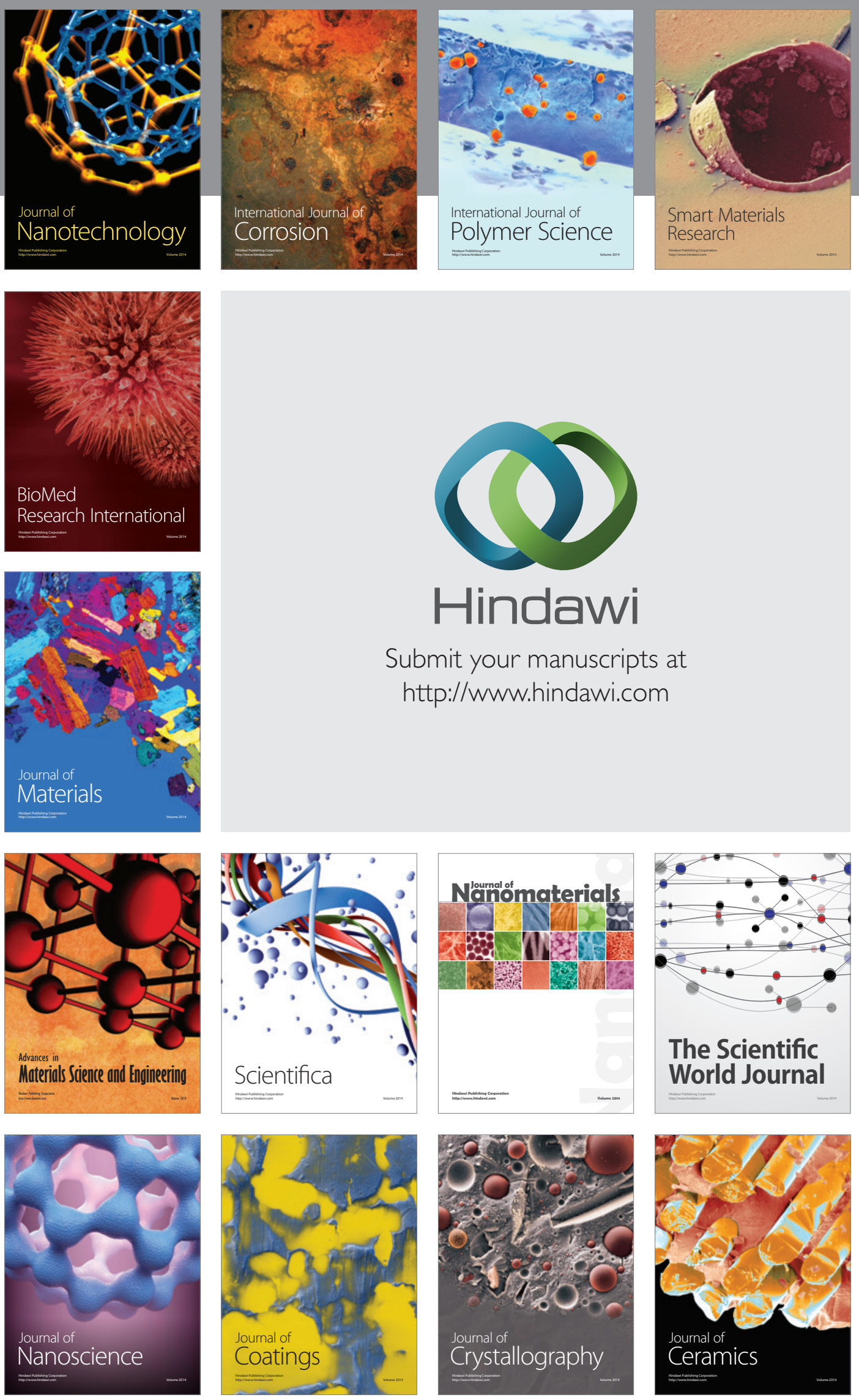

The Scientific World Journal

Submit your manuscripts at

http://www.hindawi.com

\section{World Journal}

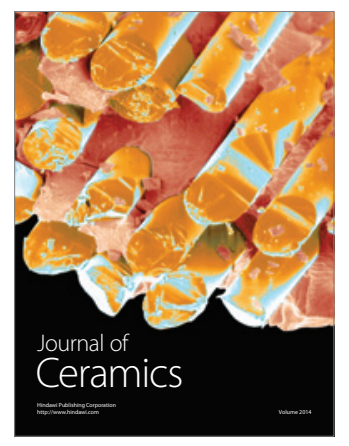

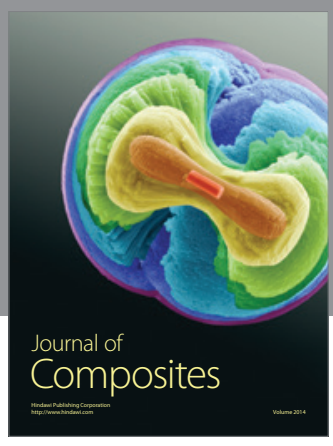
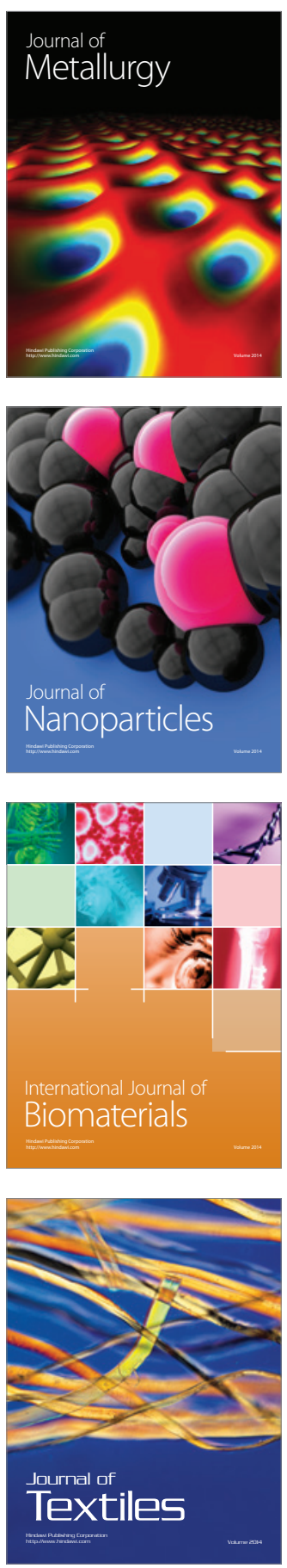